\title{
Edukasi Managemen Diabetes Berbasis Kelompok Sebaya sebagai Upaya Meningkatkan Kepatuhan Diet dan Perawatan Mandiri Penderita Diabetes Mellitus
}

\section{Dhina Widayati}

STIKES Karya Husada Kediri, Program Studi Sarjana Keperawatan, Jl. Soekarno Hatta No.7, Darungan, Kec. Pare, Kediri, Jawa Timur

Email : budinawida@gmail.com

$\begin{array}{ll}\text { Diterima } & : \text { 20 September } 2020 \\ \text { Disetujui } & : 21 \text { November } 2020 \\ \text { Dipublikasikan } & : \text { 10 Desember } 2020\end{array}$

\begin{abstract}
Abstrak
Latar Belakang dan Tujuan: Kepatuhan penderita Diabetes Mellitus (DM) dalam manajemen Diabetes tidak terlepas dari faktor informasi dan teman sebaya. Edukasi yang diberikan oleh teman sebaya akan meningkatkan informasi dan pemahaman pasien tentang manajemen pengelolaan DM yang salah satunya berupa manajemen diet dan perawatan mandiri karena merasa saling merasakan hal yang sama. Tujuan penelitian ini untuk mengetahui pengaruh edukasi manajemen diabetes berbasis kelompok sebaya terhadap kepatuhan diet dan perawatan mandiri pada penderita DM.

Metode: Pra eksperimen menjadi desain dalam penelitian ini dengan melibatkan 16 sampel yang diperoleh melalui purposive sampling. Data kepatuhan diet dan perawatan mandiri dianalisis melalui uji wilcoxon Sign Rank Test.

Hasil: Diketahui p value 0,02 (kepatuhan diet), p value 0,01 (perawatan mandiril) pada $\alpha$ 0,005 yang berarti ada beda kepatuhan diet dan perawatan mandiri sebelum dan sesudah diberikan edukasi kelompok sebaya.

Simpulan dan Implikasi: Edukasi berbasis kelompok sebaya dapat menigkatkan kepatuhan diet dan perawatan mandiri penderita DM karena edukasi yang diberikan oleh teman sebaya membuat seorang individu lebih dapat menerima dan percaya dengan pemikiran bahwa mereka merasakan hal yang sama. Metode ini dapat diterapkan sebagai salah satu pendekatan intervensi berbasis edukasi dalam menigkatkan kepatuhan diet dan perawatan mandiri penderita DM baik dalam lingkup klinik maupun komunitas.
\end{abstract}

Kata Kunci: Diet; Edukasi; Kelompok sebaya; Kepatuhan

Sitasi: Widayati D. (2020). Edukasi managemen diabetes berbasis kelompok sebaya sebagai upaya meningkatkan kepatuhan diet dan perawatan mandiri penderita diabetes mellitus. The Indonesian Journal of Health Science. 12(2), 137-146

Copyright: () 2020 Widayati. This is an open-access article distributed under the terms of the Creative Commons Attribution-NonCommercial 4.0 International License, which permits unrestricted use, distribution, and reproduction in any medium, provided the original author and source are credited.

Diterbitkan Oleh: Universitas Muhammadiyah Jember

ISSN (Print): 2087-5053

ISSN (Online): 2476-9614 


\begin{abstract}
Backgrpund and Aim: One of the levels of compliance with Diabetes Mellitus (DM) disease management is influenced by peer factors. Peer education will improve patient's understanding of management instructions for DM management and self-care through dietary adherence. The purpose of this study was to determine the effect of peer group-based diabetes management education on dietary compliance and self-care in DM sufferers.

Metohds: Pre-experiment was the design in this study by involving 16 samples obtained through purposive sampling. Dietary compliance and independent care data were analyzed using the Wilcoxon Sign Rank Test.

Results: P value 0.02 (dietary adherence), $p$ value 0.01 (self care). It means there is a difference in dietary adherence and self-care before and after peer group education.

Conclusion: Peer-based education can improve dietary adherence and self-care for DM sufferers since the education provided by peers makes an individual more likely to agree and assume that they feel the same way. This method can be applied as an education-based intervention approach in improving dietary adherence and self-care for DM sufferers both in the clinical and community settings.
\end{abstract}

Keywords: Adherence; Dietary; Education,; Peer group

\section{PENDAHULUAN}

Diabetes melitus (DM) hingga saat ini masih menduduki prioritas penelitian nasional untuk penyakit degeneratif setelah penyakit kardiovaskuler, serebrovaskular, dan geriatrik (Soewondo, 2011). Perkiraan WHO terkait prevalensi penyakit ini pada tahun 2030 mencapai 300 juta orang (Tripathy, 2008). DM merupakan penyakit kronik yang ditandai peningkatan nilai kadar gula darah. Manajemen DM dapat dilakukan melalui 4 pilar yakni : pendidikan kesehatan, diet, exercise dan konsumsi obat anti diabetikum. Kontrol kesehatan, khususnya cek gula darah secara rutin berkorelasi dengan keberhasilan pengelolaan 4 pilar tersebut (Misnadiarly, 2006).

Pada pengelolaan DM salah satu komponen yang cukup penting dalam menjaga kestabilan gula darah adalah manajemen diet. Asupan nutrisi yang sesuai dengan jenis diet pada penderita DM dapat menjaga kestabilan kadar lipida dan berat badan dalam batas normal sehingga dapat meningkatkan derajat kesehatan dan meminimalkan terjadinya komplikasi (Almatsier, 2005). Penderita diabetes diharuskan mempunyai komitmen dalam mengikuti dan mematuhi program diet yang telah direncanakan oleh tim kesehatan agar gula darah dapat terkontrol dengan baik (Misnadiarly, 2006).

Hasil studi pendahuluan menyatakan bahwa $80 \%$ dari 20 penderita DM mengatakan kesulitan dalam mematuhi diet Ketidakpatuhan ini disebabkan oleh kuranngnya informasi pengelolaan diet dan perawatan mandiri DM. Penyakit Diabetes yang ditandai dengan peningkatan kadar gula darah bila tidak dikelola dengan baik maka akan beresiko menimbulkan 
beberapa komplikasi, baik yang bersifat makrovaskuler maupun mikrovaskuler. Komplikasi makrovaskuler dapat berupa hipoglikemi, koma diabetikum, gangren. Sedangkan komplikasi mikrovaskuler dapat berupa retinopati dan neuropati (Tjokroprawiro, 2011).

Salah satu upaya pencegahan komplikasi dapat dilakukan melalui pemberian edukasi kesehatan yang dapat meningkatkan pengetahuan pasien dalam manajmeen DM dalam hal ini kepatuahan diet dan meningkatkan kemandirian pasien dalam pengelolaan kesehatannya dan perawatan diri secara mandiri (Warsi et al,2004) dan Widayati (2014).

Menurut penelitian yang dilakukan oleh Niven (2005) terdapat beberapa faktor yang mempengaruhi tingkat kepatuhan pasien dalam pengelolaan Diabetes yakni : pengetahuan dan pehamanan tentang isntruksi yang boleh dan tidak boleh dilakukan, interaksi dengan petugas kesehatan dalam perencanaan diet, keyakinan diri, kepribadian, sikap dan support system dalam hal ini yang berasal dari keluarga maupun teman sebaya yang mempunyai kondisi yang sama. Dalam manajemen penatalaksanaan diabetes dibutuhkan komitmen bersama serta partisipasi aktif dari beberapa elemen, yakni tenaga kesehatan, keluarga dan masyrakat secara luas (Tjokroprawiro, 2007) (Sidani, 2009). Keterlibatan dari Support system tersebut berkorelasi dalam meningkatnya kepatuhan pengelolaan penyakit DM tipe 2 (Friedman, 2010). Hal ini sesui dengan penelitian Ilkafah (2011) yang menyatakan $45 \%$ responden mengalami peningkatan kemandirian dalam pengelolaan DM setelah pemberian intervensi peer group support. Intervensi dikemas dalam bentuk pemberian informasi melalui edukasi yang disampaikan oleh peer (teman sebaya) dalam setting group (kelompok) memungkinkan timbulnya rasa kebersamaan yang berkorelasi dengan psikologis pasien (Widayati, 2020). Menurut Smith, et al (2011) peer group merupakan suatu wadah bagi sekelompok penderita DM untuk saling berbagi pengalaman, saling bertukar informasi dan saling memberi dan menerima dukungan emosional. Melalui forum ini sesama penderita akan menjadi lebih terbuka untuk menyampaikan permasalahan dan pengalaman yang dialami. Edukasi yang diberikan oleh teman sebaya akan meningkatkan pemahaman pasien tentang intruksi dan lebih termotivasi dengan adanya dukungan dari teman sebaya tersebut. Penelitian ini bertujuan untuk mengetahui pengaruh edukasi managemen diabetes berbasis kelompok sebaya terhadap kepatuhan diet dan perawatan mandiri penderita $\mathrm{dm}$.

\section{METODE PENELITIAN}

Studi ini menggunakan desain pra eksperimen dengan melibatkan sampel sebanyak 16 responden yang diperoleh melalui purposive sampling dengan kriteria inklusi : (1) Penderita DM tipe 2 yang mengalami ketidakpatuhan diet, (2) Penderita DM tipe 2 usia 30-60 tahun dan kriteria eksklusi: Penderita DM tipe 2 yang mengalami komplikasi seperti stroke, infark jantung, gagal ginjal, kelainan hati berat, neuropati berat dan gangren diabetikum. Penelitian dilakukan di wilayah Puskesmas Bendo Desa Bendo, Kec. Pare, Kab. Kediri 


\section{HASIL}

Berdasarkan tabel 1 diketahui bahwa sebagian responden berusia $46-50$, sebagian besar $(68,8 \%)$, jenis kelamin laki-laki dengan riwayat pendidikan mayoritas kategori pendidikan menengah (SMP/SMA). Sedangkan berdasarkan pekerjaan diketahui sebagian mempunyai riwayat pekerjaan wiraswasta. Dengan lama menderita DM dalam rentang 1-2 tahun.
Tingkat kepatuhan diet responden sebelum diberikan intervensi dalam kategori sedang, dan setelah intervensi terdapat $50 \%$ responden dengan tingkat kepatuhan dalam kategori tinggi (Tabel 2). Berdasarkan tabel 3 diketahui perawatan mandiri sebelum dilakukan intervensi terdapat 93,8\% dalam kategori rendah, dan setelah pemberian intervensi menunjukkan $75 \%$ dalam kategori tinggi.

Tabel 1. Karakteristik Responden

\begin{tabular}{lcc}
\hline \multicolumn{1}{c}{ Kategori } & N & \% \\
\hline Usia & 3 & 18,8 \\
$40-45$ th & 8 & 50,0 \\
$46-50$ th & 5 & 31,3 \\
$>51$ th & 11 & 68,8 \\
Jenis kelamin & 5 & 31,3 \\
$\quad$ Laki-Laki & 2 & \\
$\quad$ Perempuan & 12 & 12,5 \\
Pendidikan & 2 & 75,0 \\
$\quad$ Rendah (SD) & 2 & 12,5 \\
$\quad$ Menengah (SMP/SMA) & 1 & 12,5 \\
Tinggi (Diploma/Sarjana) & 1 & 6,3 \\
Pekerjaan & 8 & 6,3 \\
$\quad$ Tidak bekerja & 4 & 50 \\
PNS & & 25 \\
$\quad$ Wirausaha & 12 & 75 \\
$\quad$ Wiraswasta & 4 & 25 \\
Pensiunan & & \\
Lama menderita dibetes & & \\
$\quad$ 1 tahun & 2 tahun &
\end{tabular}

Tabel 2. Tingkat Kepatuhan Sebelum dan Sesudah Intervensi

\begin{tabular}{|c|c|c|c|c|c|}
\hline \multirow{2}{*}{ Tingkat Kepatuhan } & \multicolumn{2}{|c|}{ Pre Test } & \multicolumn{2}{|c|}{ Post Test } & \multirow{2}{*}{ P Value } \\
\hline & $\mathrm{f}$ & $\%$ & $\mathrm{f}$ & $\%$ & \\
\hline Rendah & 2 & 12,5 & 1 & 6,25 & 0,020 \\
\hline Sedang & 12 & 75 & 7 & 43,75 & \\
\hline Tinggi & 2 & 12,5 & 8 & 50 & \\
\hline
\end{tabular}

Tabel 3. Perawatan Mandiri Sebelum dan Sesudah Intervensi

\begin{tabular}{lllrlrr}
\hline & $\begin{array}{c}\text { Perawatan } \\
\text { Mandiri }\end{array}$ & $\sum$ & F & Mean & SD & \multicolumn{1}{c}{$\boldsymbol{F}$ value } \\
\hline Sebelum & Rendah & 15 & 93,8 & 1,00 & 0,250 & 0,001 \\
& Tinggi & 1 & 6,3 & & & \\
Sesudah & Rendah & 4 & 25 & 1,75 & 0,403 & \\
& Tinggi & 12 & 75 & & & \\
\hline
\end{tabular}




\section{PEMBAHASAN}

Mayoritas responden sebelum diberi intervensi edukasi berbasis kelompok sebaya mempunyai kepatuhan diet dalam kategori sedang. Menurut teori perubahan perilaku Notoatmojo, (2007) sebuah tindakan dalam hal ini (kepatuhan diet) akan terbentuk apabila individu tersebut mengerti dan memahami tindakan tersebut. Hal ini menunjukkan bahwa pengetahuan sangat berkorelasi dengan keberhasilan perubahan perilaku (Isnaeni, 2017). Bila dikaitkan dengan data umum pada penelitian ini menunjukkan bahwa mayoritas responden $\quad(75 \%)$ mempunyai riwayat pendidikan tingkat menegah dan atas. Hal ini berimplikasi pada proses berfikir secara kritis, pemahaman dalam penerimaan informasi, dan kemampuan dalam akses informasi melalui media massa maupun media sosial yang berkaitan dengan kepatuhan diet pada penderita DM. Sehingga dalam hal ini sebelum pemberian intervensi, tingkat kepatuhan diet dalam kategori sedang.

Masih belum maksimalnya informasi yang diterima oleh penderita DM terkait manajemen diet merupakan salah satu hambatan bagi penderita dalam menjalankan diet dengan benar dan taat. Hal ini sejalan dengan penelitian Arini,dkk (2020) yang menyatakan pengetahuan responden berkorelasi secara bermakna dengan tingkat kepatuhan dalam menjalankan program diet DM yang telah diprogramkan. Penyebab utama masih rendahnya kepatuhan terhadap diet penderita DM berkorelasi dengan minimnya dukungan baik yang berupa dukungan informasi maupun dukungan sosial dari teman sebaya yang bersedia mendengarkan keluhan dan membantu menyelesaikan masalah dalam menjalankan diet. Hal ini sejalan dengan studi yang dilakukan Smet (2004) dan Sugiharto (2020) menyatakan bahwa dukungan informasi dari profesional kesehatan dan dukungan sosial dari teman atau keluarga merupakan strategi dalam meningkatkan kepatuhan menjalankan program pengobatan sehingga perlu pembuatan program edukasi oleh sesama diabetisi dalam wadah diabetes class.

Setelah pemberian intervensi edukasi berbasis kelompok sebaya, kepatuhan diet mayoritas responden mengalami peningkatan. Sebagian besar responden setelah mendapatkan edukasi yang disampaikan oleh teman sebaya yang terlebih dulu dilatih oleh peneliti mampu melakukan pengelolaan diet dengan benar (mulai dari pemilihan jenis dan konsumsi yang sesuai baik dari segi jumlah maupun jadwal). Responden dapat menerapkan waktu yang telah dijadwalkan. Pada studi ini didapatkan peningkatan tingkat kepatuhan responden setelah pemberian intervensi dan secara statistik menunjukkan intervensi edukasi berbasis kelompok sebaya berpengaruh terhadap kepatuhan diet penderita DM. Hasil ini sejalan dengan studi yang dilakukan oleh Ilkafah (2011) yang menunjukkan terjadinya peningkatan self efficacy manajemen DM pada responden setelah pemberian intervensi peer goup education. Hal ini menunjukkan bahwa seorang individu yang telah mendapatkan informasi melalui pemberian edukasi oleh kelompok sebaya akan mempunyai keyakinan diri yang positif dalam pengelolaan DM dan 
aktivitas perawatan diri secara mandiri terutama dalam pelaksanaan salah satu pilar manajemen DM yakni kepatuhan diet, (Endra,dkk,2019). Perilaku yang dilakukan oleh seorang individu didasari oleh intensi/niat dan motivasi yang didapatkan responden melalui dukungan yang berasal dari teman sebaya, termasuk didalamnya dukungan informasi dan sosial, (Anggi,2010). Perubahan perilaku responden dalam menjalankan diet secara patuh merupakan efek dari informasi terkait bagamaina pengelolaan diet yang dianjurkan untuk penderita DM dan sharing pengalaman antar sesama responden dalam menjalankan diet secara patuh (terakit hambatan dan strategi yang dapat dilakukan) yang didapatkan melalui edukasi berbasis kelompok sebaya. Selain itu, pada intervensi yang berbasis kelompok memungkinkan antar individu saling memberikan penguatan sehingga masing-masing individu semakin termotivasi untuk mematuhi diet agar gula darah dapat stabil dan terhindar dari komplikasi DM yang lebih parah (Steinsbekk,2012). Pemberian dukungan sosial bagi dan oleh sesama penderita DM dalam setting kelompok memungkinkan terjalin rasa kebersamaan dan persaudaran yang tinggi yang dapat memuncukan perasaan ingin sehat bersama sama sehingga masing masing invidu saling memberikan motovasi, keyakinan diri dan persepsi yang positif untuk menjaga kestabilan kadar gula darah melalui kepatuhan menjalankan diet DM (Heisler,2007) dan Paskalini (2017). Seorang individu yang memiliki persepsi yang postif tehadap pengelolaan diet akan mempunyai keyakinan yang baik dalam melaksanakan pola diet yang menjadi pilar utama dalam manajemen kestabilan kadar gula darah penderita DM (Greco, 2001) dan (Misnadiarly, 2006). Walupun demikian pada studi yang dilakukan oleh Dewi (2018) menunjukkan hasil yang tidak sejalan dengan penelitian ini, yang menyatakan dukungan sosial dari keluarga tidak berkorelasi secara bermakna dengan kepatuhan diet penderita DM karena dukungan instrumental belum sepenuhnya diberikan oleh keluarga terkait penyediaan jenis makanan yang sesuai.

Strategi penyampaian informasi melalui edukasi, media juga mempunyai peran yang penting dalam meningkatkan efektifitas transfer informasi tersebut. Pada studi ini, media informasi yang diberikan dikemas dalam bentuk booklet dengan isi yang aplikatif terkait diet yang harus dilaksanakan (jenis makanan yang mudah didapatkan disekitar kita beserta contoh gambar dan jumlah kalorinya, jumlah porsi penyediaan yang dikonversikan dengan alat ukur yang sering dipakai yakni dalam ukuran potongan berapa $\mathrm{cm}$ atau takaran gram yang dapat juga dikonversikan dengan takaran sendok apabila responden tidak mempunyai timbangan, jadwal makan yang digambarkan dengan diagram lingkaran menyesuaikan bentuk Jam yang didalamnya dituliskan waktu pilihan untuk makan) yang dapat dilakukan secara mandiri. Hal ini sejalan dengan studi Niven (2005) yang menyatakan penggunaan media informasi dalam bentuk booklet dan audio dapat meningkatkan kepatuhan diet penderita DM.

Perawatan mandiri DM pada responden sebelum intervensi menunjukkan 93,8\% dalam kategori 
rendah dan $6,2 \%$ dalam kategori tinggi. Hampir semua responden kurang mengetahui perawatan secara mandiri, sehingga pasien hanya bisa melakukan perawatan dengan bantuan perawat atau keluarganya, dan pasien DM tidak pernah memperhatikan pola makan yang seharusnya menjadi perhatian, responden mengikuti pola makan yang biasanya dimakan oleh keluarganya tanpa memperhatikan kandungan dalam makanan.

\section{Perawatan}

mandiri

manajemen diabetes komponen latihan fisik dan monitoring gula darah terdapat 93,8\% dalam kategori rendah, karena responden tidak pernah memantau perkembangan gula darah dan tidak pernah melakukan aktifitas misalnya olah raga, karena mereka belum mengetahui informasi tersebut. Selain itu pada komponen konsumsi obat anti diabetik terdapat $100 \%$ dalam kategori rendah, karena mereka tidak pernah memperhatiakan kondisi perkembangan DM yang terjadi pada dirinya, dan mereka hanya bisa tergantung oleh pemeriksaan dokter atau perawat yang berada pada rumah sakit. Sehingga pada penelitian ini sebelum dilakukan intervensi pasien DM tipe II seluruhnya mereka tidak pernah memperhatikan dirinya sendiri dan selalu menggantungkan perawatan pada perawat atau dokter ketika melakukan pemeriksaan di rumah sakit.

Setelah pemberian intervensi menunjukkan perawatan mandiri responden, $25 \%$ dalam kategori rendah dan $75 \%$ dalam kategori tinggi. Peningkatan perawatan mandiri pada responden dipengaruhi oleh beberapa factor, diantaranya: usia, jenis kelamin, pendidikan, pekerjaan, lama menderita, dan kadar gula darah dan dukungan sosial. Berdasarkan data yang didapat dari penelitian bahwa perhitungan data umum denagn kreteria usia 40-45 tahun terdapat $18,8 \%$ dimana pada usia ini mereka sudah terkena DM karena kurangnya memperhatikan pola makan setiap harinya. Sedangkan berdasarkan kriteria usia 46-50 tahun peneliti menemukan pasien DM terdapat 50\% karena mereka selalu tidak memperhatikan perawatan dan cara melakukan hidup sehat. Dan berdasarkan kreteria usia $>50$ tahun peneliti menemukan pasien DM tipe II terdapat $31,3 \%$ karena semakin usia bertambah maka semakin tua juga semua organ yang terdapat pada pasien DM, sehingga dari mereka juga kurang memperhatikan perkembangan penyakit yang sedang diderita oleh pasien. Namun pada penelitian yang dilakkukan oleh Erningwati (2015), usia, jenis kelamin dan lama menderita DM tidak berhubungan secara signifikan dengan perawatan diri secara mandiri penyandang DM Tipe2, yang berpengaruh dalam perilaku perawatan diri adalah dukungan sosial dan efikasi diri.

Selain berdasarkan usia, jenis kelamin juga mempengaruhi masa perkembangan yang sering terjadi pada pasien dengan penyakit DM yang mana berdasarkan kriteria jenis kelamin terdapat $68,8 \%$ pada lakilaki dan $31,3 \%$ pada perempuan, karena pada jenis kelamin laki-laki akan lebih mudah atau sering terkena DM dari pada perempuan yang mana dipengaruhi oleh gen atau cara perawatan secara mandiri. Sedangkan berdasarkan pendidikan peneliti menemukan dengan riwayat pendidikan SD terdapat $12,5 \%$, dan 
75\% dengan pendidikan SMP/SMA dan $12,5 \%$ dengan pendidikan tinggi (diploma/sarjana). Hal ini dilihat dari riwayat pendidikan akan mempengaruhi proses pengetahuan yang dimiliki oleh responden, karena semakin tinggi ilmu yang mereka dapatkan dan koping cara melakukan perawatan secara mandiri maka akan mempengaruhi tingkat keberhasilan melakukan manegemant dalam perawatan secara mandiri (Ariani, 2020). Individu dapat melakukan pemantauan pola makan dan gaya hidup yang sehat setelah mendapatkan informasi penegalolaan penyakit DM sehingga dapat menjadi individu yang sejahtera dan dapat hidup layak seperti individu lainnya (Sutandi, 2012). Selain itu pekerjaan juga akan mempengaruhi strategi dalam pengambilan keputusan untuk melakukan perawatan secara mandiri yang dilihat berdasarkan kreteria tidak bekerja terdapat $12,5 \%$ dan 6,3\% terdapat pada kreteria PNS dan wirausaha. Pekerjaan yang paling banyak pada responden $50 \%$ diantranya wiraswasta dan $25 \%$ pensiunan, dimana pada pekerjaan ini dapat mempengaruhi tingkat keberhasilan dilakukannya intervensi pada responden, sehingga pada responden ini mereka dapat melakukan managemen secara mandiri.

Berdasarkan lama menderita DM terdapat $75 \%$ responden dengan DM dengan lama 1-2 tahun mereka mengalami penyakit ini tanpa mengerti pentingnya melakukan perawatan secara mandiri dan tidak tergantung oleh bantuan orang lain. Selain itu terdapat $25 \%$ dari responden dengan lama menderita $>2$ tahun, mereka hanya melakukan pemeriksaan kesehatan ketika merasakan nyeri atau sakit ketika sudah parah, dan kurang menngerti mengenai perawatan secara mandiri, yang semestinya harus bisa dilakukan secara mandiri oleh pasien DM .

\section{SIMPULAN}

Intervensi edukasi managemen diabetes berbasis kelompok sebaya dapat meningkatkan kepatuhan diet dan perawatan mandiri pada penderita Diabetes Mellitus.

\section{SARAN}

Intervensi edukasi manajemen DM berbasis kelompok sebaya dapat diterapkan sebagai salah satu pendekatan intervensi berbasis edukasi dalam menigkatkan kepatuhan diet dan perawatan mandiri penderita DM baik dalam lingkup klinik maupun komunitas.

\section{DAFTAR PUSTAKA}

Almatsier, S.(2005). Prinsip Dasar Ilmu Gizi. PT. Gramedia Pustaka Utama, Jakarta.

Anggi, DS \& Rahayu, S.(2010). Faktor-Faktor Yang Berhubungan Dengan Kepatuhan Diet Pada Pasien DM Tipe2. Jurnal Ilmiah Keperawatan STIKES Hang Tuah Surabaya, Vol.15, No. 1, 124-138

Arini, ED.,Murti, HI.,Signa, AG. (2020). Faktor Yang Mempengaruhi Tingkat Kepatuhan Diet Pada Pasien DM Tipe 2 di Kec. Sumbang Banyumas. Journal of Bionursing, Vol.2 No. 1, 63-67

Dewi, T., Amir, A., Sabir, M.(2018).Kepatuhan Diet Pasien DM Berdasarkan 
Tingkat Pengetahuan dan Dukungan Keluarga Di Wilayah Puskesmas Sudiang Raya. Media Gizi Pangan, Vol. 25, No. 1,5563

Endra, C.E, Yuanita., Antari, I.(2019).Perawatan Diri (Self Care) Pada Pasien DM Tipe2. Jurnal Kesehatan Madani Medika, Vol. 10, No. 2, 85-91.

Erningwati, A.E.(2015). Dukungan Sosial \& Perilaku Perawatan Diri Penyandang DM Tipe 2. Jurnal Info Kesehatan, Vol.14, No.2, 952-966

Friedman, M.M., Bowden, V.R., \& Jones, E.G. (2010). Buku ajar keperawatan keluarga: Riset, teori, \& praktik (Achir Yani, Agus Sutarna, Nike Budhi Subekti, Devi Yulianti, Novayanti Herdina, Penerjemah). Jakarta: EGC

Greco, P., Pendley, J.S., McDonell, K., Reeves, G., (2001). A Peer Group Intervention for Adolescents With Type 1 Diabetes and Their Best Friends, Journal of Pediatric Psychology. Vol.26, No.8, 485-490.

Heisler, M., (2007). Overview of Peer Support Models to Improve Diabetes Self Management and Clinical Outcomes, Diabetes Spectrum, Vol. 20, No.4, 214-220.

Ilkafah, 2011. Thesis: Pengaruh Peer Group Support Terhadap Self Efficacy Kontol Gula Darah dan Self Care Activities pada Penderita Diabetes Mellitus Di Puskesmas Mantup
Kabupaten Lamongan.

Surabaya: $\quad$ Fakultas

Keperawatan UNAIR.

Isnaini, N\&Helmi, A.S.M, .(2017).Pengetahuan dan Motivasi Menigkatkan Kepatuhan diet Penderita DM Tipe2. Mediasains:Jurnal Ilmiah Ilmu Kesehatan, Vol. 15, No. 3, 136-141

Misnadiarly. (2006). Diabetes Mellitus: Gangren, Ulcer, Infeksi. Mengenal Gejala,Menanggulangi, dan Mencegah Komplikasi. Jakarta: Pustaka Populer Obor

Notoatmojo,S.(2007). Ilmu Kesehatan Masyarakat. Jakarta : Rhineka Cipta.

Niven, N., (2005). Psikologi Kesehatan. Jakarta: Erlangga.

Paskalini, R.V., Mario, E.K., Malara, R. (2017). Hubungan Dukungan Sosial dan Motivasi Dengan Perawatan Mandiri Pada Pasien DM di Poliklinik Penyakit Dalam RSUD Mokopido. EJournal Keperawatan, Vol. 5, No. 1, 1-10

Sidani, S.\& Fan,

L.(2009).Effectiveness of Diabetes Self-management Education Intervention Elements: A Meta-analysis. Canadian Journal of Diabetes, Vol. 33, No. 1, 1826.

Smet. (2004). Psikologi kesehatan. Jakarta: PT. Grasindo

Smith, S. M., Paul, G., Kelly, A., Whitford, D. L., O'Shea, E., \& O'Dowd, T. (2011). Peer Support for Patients with 
Type 2 Diabetes: Cluster Randomised Controlled Trial. British Medical Journal (BMJ) Vol.342. No.71

Soewondo.P.(2011). Prevalence,

Cahracteristic, and

Predictors of Prediabetes in Indonesia. Medical Journal. Indonesia, Vol.2, No. 20, 283-294

Sugiharto., Mudaliya, E., Riskiana, M., Bagus, P.B.(2020). Peningkatan Ketrampilan Perawatan Mandiri Mellaui Diabetes Class Pada Pasien DM Tipe 2 Peseta Prolanis di Wilayah Kerja Puskesmas Kedungwani. The 11 th University Research Collogium.Univ. Aisyiyah Yogyakarta, 146149.

Sutandi, Aan.(2012).Self Management Education (DSME) Sebagai Metode Alternatif dalam Perawatan Mandiri Pasien DM di Keluarga. Widya Kesehatan, Vol. 29, No.323, 54-49

Steinsbekk et al. (2012), “Group Based Diabetes SelfManagement Education Compared to Routine Treatment for People with
Type 2 Diabetes Mellitus. A Systematic Review with Metaanalysis".

Tjokroprawiro, A., (2007). Buku Ajar Ilmu Penyakit Dalam I Fakultas Kedokteran Universitas Airlangga RSU Dr. Soetomo Surabaya. Airlangga University press.

Tjokroprawiro, A., (2011). Hidup Sehat dan Bahagia Bersama Diabetes: Panduan Lengkap Pola Makan untuk Penderita Diabetes. Jakarta: P.T. Gramedia Pustaka Utama.

Tripathy, B. B. (2008). Textbook of Diabetes Mellitus. Volume I. Jaypee Brothers Medical Publisher

Widayati,D \& Afrian,N.N.(2020)

Kreasiki Gymnastic in Reducing The Stress Level of DM. Jurnal Info Kesehatana, Vol.18, No. 1, 18-27.

Widayati,D \& Siswoaribowo, A.(2014).Peningkatam Self Care Activities Penderita DM Tipe 2 Melalui Inovation Intervention Berbasis Teori Self Care. Jurnal Ilmu Kesehatan, Vol., No.6, 351-356 